\title{
The Similarities Between the Errors in the Mother Tongue of the Autistic Children and the Target Language of the Second/Foreign Language Learners
}

\author{
Tahani Abdulrahman Al-absi \\ Department of Linguistics, School of Language Development, Potti Sreeramulu Telugu University, Hyderabad, India
}

Email address:

absitahani@gmail.com

\section{To cite this article:}

Tahani Abdulrahman Al-absi. The Similarities Between the Errors in the Mother Tongue of the Autistic Children and the Target Language of the Second/Foreign Language Learners. International Journal of Applied Linguistics and Translation. Vol. 7, No. 1, 2021 , pp. $21-26$. doi: $10.11648 /$ j.ijalt.20210701.12

Received: March 10, 2021; Accepted: March 24, 2021; Published: March 30, 2021

\begin{abstract}
This paper presents the first investigation of the errors in the mother tongue of the children with autism, and compare between these errors and the errors in the production of Arab learners of English as second/foreign language. Based on the previous literature, the current study noted that language delay and the impaired social skills in the children with autism are the most prominent reasons which resulted in their impaired skills of language. In addition to, primary reasons affected the production of the second /foreign language such as the delayed learning of the target language, and the lack of interaction with the native speakers in social settings. Overall, these similar reasons between the two groups led to similar errors in the productions of their native and target languages. Aims: The primary goal of the present study is to explore the similarities between the performance of the children with autism when they use their mother tongue, and the errors in the production of Arab learners of English as second /foreign language when they use the target language. Methods \& Procedures: The sample of this study consisted of two Yemeni children with high functioning autism aged 7;6 and 8;3 years. The examiner used the expressive language task to elicit the morpho-syntactic structures from the two cases, and compared it to the previous literature of Arab learners of English as second /foreign language, to find out the similarities between the errors in their productions. Results: The findings of this study revealed the similarities between the errors which occur in the answers of the autistic children when they use their mother tongue, and the errors which occur in the production of Arab learners of English as second /foreign language due to their delayed learning of the native/target languages. These errors classified into omission, substitution, or deletion of grammatical structures explored in this study and included (adjectives, preposition, articles, subjectverb agreement and plurality). The children with autism and the learner of English as second/foreign language substituted the order of the adjectives at the sentence level, omitted and overused the articles, substituted the prepositions with others, replacing the feminine suffixes with masculine suffixes in the production of the autistic children, and omitting the $3^{\text {rd }}$ person singular in the production of the ESL/EFL learners resulted in subject-verb disagreement, and impaired plurality by replacing the singular nouns with plural nouns in the learners of English as second/foreign language or the opposite in the children with autism.
\end{abstract}

Keywords: Similarities, Autistic Children, ESL/EFL Learners, Mother Tongue, Errors

\section{Introduction}

Autism is a neurodevelopmental disorder characterized by three types of impairments included: impaired social skills, impaired or delay spoken language and skills of communication, and repetitive and stereotyped behaviours [6]. The delay onset of the spoken language in the children with autism is one of the deficits which used as diagnostic criteria for autism [6]. The autistic individual has impairments in communication included delay or lack in the development of the spoken language, difficulty to start and sustain a conversation with the others, obsessed with their topic of interest or idiosyncratic language, difficulty with the spontaneous imaginary play or the imitative role of play 
proper to their age [5]. Language development in the children with autism is often delay and heterogeneous [14]. There is a correlation between language delay in the parents of the autistic children when they were children and their autistic children with language delay [18]. The language in the autistic children characterized with impairments as mentioned by Leo Kanner [17] and included pronoun reversal (using the pronoun you instead of the pronoun I), echolalia (repeating what the others said to the children and there are delayed echolalia and immediate echolalia), and language delay (sometime till 5 years). There are similarities between the abilities of language in the children with autism and the learners of the second/foreign language due to the delayed acquisition of the mother tongue in the children with autism because of the developmental processes, and the delayed exposure to the target language in the ESL/EFL learners [16]. The acquisition of the mother tongue is delayed in the children with autism in comparison to the typically developing children who acquire it earlier and gradually. In addition to, the language deficits in the children with autism included difficulties with prepositions, auxiliaries, pronouns and verb inflections [10]. The children with autism can be classified into three groups included: children with normal language, children with good vocabulary but face difficulties with the grammatical structures, and other with impaired language [26]. There is a significant difference between the performance of language in the learners before and after maturation, the learners who acquire it early before the maturation perform better than the learners who acquire it after the maturation, even for the learners of their native language as age has its flattening affects in adulthood and linear affects in childhood [20].

\subsection{Literature Review}

Eigsti \& Bennetto conducted a study to test the grammatical structures in the language of children with autism, matched to a group of the typically developing children. The stimuli of this study were grammatical and ungrammatical structures to test the two groups of children by using the judgment-task. The findings indicated that the children with autism made more errors than the typically developing group of children in the third person singular and the present progressive [13].

Bartolucci, Pierce, and Streiner used 14 grammatical morphemes appeared in Brown's (1973) study to examine the grammatical structures in ten children with autism aged 10.9 years, compared to a group of children with ID but without ASD, and another group of ten TD children. The findings of this study indicated that there were similarities between the performances of the ASD group of children and the ID group of children, whereas the TD group of children performed better than them, and the difference between them was significant. Moreover, the findings reported that the children with autism omitted the articles, auxiliary and copula verbs, past tense, third person present tense, and present progressive [9].

Roberts et. al. examined tense marking in a group of children with autism were divided into children with normal language and children with impaired language, compared to a group of children with SLI. The performance of the autistic children with impaired language was similar to the performance of the 5 years old children with SLI on the third person singular but was better than them on the past tense [21].

Eigsti et. al. conducted a study to explore the development of the morphological and syntactic structures in the language of the children with autism. The finding of study showed that the 5 years old children with autism produced less complex structure, in comparison to their younger control TD group of children who matched them on receptive vocabulary and non-verbal IQ (12).

Bartolucci and Albers examined the inflectional morphemes in a group of children with autism aged 6-12 years, compared their performance to a group of mentally retarded children without autism, and a group of typically developing children. The findings of this study reported that the performances of the three groups of children were similar on the inflections of the present progressive tense, but there was a difference between their performances on the inflections of the past tense, as the performance of the ASD group of children was impaired, and less than the performances of the other participated groups [8].

Durrleman \&zufferey investigated the syntactic deficits in the children with autism. The findings indicated that the children with autism produced syntactic deficits included omitting the article, absence of the plural (-s), difficulties with the reflexives, used the progressive (-ing) more than the past tense (-ed), impaired use of the third person singular (-s), difficulties with the question included (null subject, absence of the subject auxiliary inversion and absence of the auxiliary [11].

\subsection{Research Questions}

What are the similarities between the errors which occur in the production of the autistic children and the Arab learner of English as second/foreign language due to the delayed spoken language in the children with autism and the delayed learning and exposure to the second /foreign language in the learners of the target language?

\subsection{Purpose of the Study}

The main objective of the present study is to investigate the similarities between the errors in the production of the mother tongue in the autistic children, and the production of the target language in the learners of the second/foreign language. Also, this research conducted to attract the attention of the people in charge of the autistic individuals to these similarities. Consequently, the findings of the current study can help them through using the teaching curriculums and methods of the second/foreign language in teaching them their mother tongue. Particularly, the category of the high functioning children with autism as their level of language is good, but include some deficits in language can be treated by 
using an appropriate teaching methods and plans.

\section{Methods \& Procedures}

\subsection{Sample / Participants}

The participants of this study were two Yemeni verbal children with high functioning autism. Ahmed aged 7;6 years old and Mohammad aged 8;3 years old. Both of them were diagnosed with autism and met the criteria of DSM-IV. The examiner visited them in their homes, and both of them had no hearing or vision impairments, but Ahmed had severe symptoms of anxiety controlled with medication affected his attention and span of concentration, and Mohammad used formal style of vocabulary and grammatical structures. Both of them had the ability to improve their language and overcome the challenges which face them when they use their spoken language. Most of these errors were due to reasons such as unqualified autism center, unqualified teachers, inappropriate curriculum, in addition to busy families play no role in improving the language of these children.

\subsection{Instrument}

The examiner used the Expressive Language Task to facilitate the morpho-syntactic structures of the study and collect accurate data from the two participants. Further, the abilities of the children with autism in the expressive language is better than in the receptive language. Therefore, the researcher used this task for collecting the grammatical structures from them. In addition to, materials included pictures illustrated the morpho-syntactic structures, and stimuli represented the grammatical structures of the study.

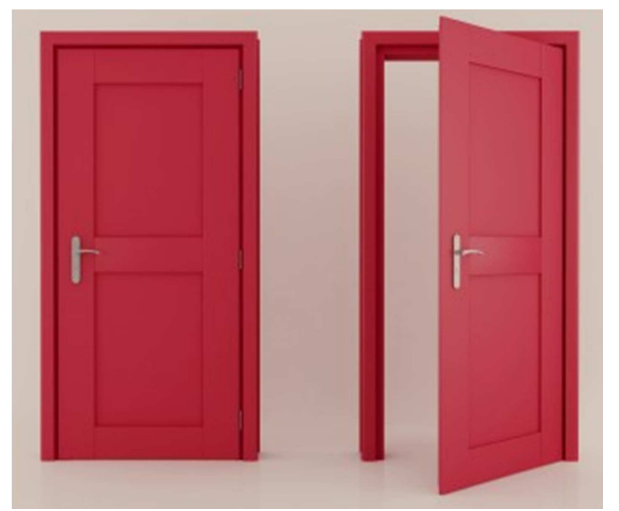

Figure 1. Illustrates the opposite adjectives (opened door \& closed door) and used for examining the order of adjectives in the production of the ASD children.

\subsection{Data Collection Procedures}

The researcher used the expressive language task which included pictures in all the tasks. Each page included two pictures or one picture placed in front of the participants one by one. The researcher asked the participant a question, to elicit one of the morpho-syntactic structures, and scored the answers. In the test of adjectives, the examiner used stimulus such as (this door is open, what about the other door?). The participant was required to reply with (a closed door) to be scored with correct. The morpho-syntactic structures which examined in this study included adjectives, prepositions, articles, subject-verb agreement and plurality. Additionally, the collected data were classified based on Cook's (1999) into substitution, omission, and insertion.

\section{Results}

\subsection{Adjectives}

In the Modern Standard Arabic, Adjectives inflect to gender (masculine or feminine), number (singular or plural), case (nominative, accusative or genitive), definiteness (definite or indefinite) and degree (comparative and superlative). Moreover, the noun precedes the adjective in Arabic, for instance (the sea the red) instead of (the red sea) $[22,23]$.

Examples adapted from [24] about errors made by Arab learners of English in ordering the adjectives at the sentence level.

He is a man tall.

They are soldiers brave.

In the production of the autistic children, they made the same errors in ordering the adjectives at the sentence level. In the present study, Ahmed made $12 \%$ of errors in ordering the adjectives in his answers, and Mohammad increased it to $16 \%$ of his answers.

Table 1. Illustrates the errors in ordering the adjective at the sentence level in the production of the autistic children.

Bottle closed instead of a closed bottle.

Bottle opened instead of an opened bottle.

Man short instead of a short man.

Man tall instead of a tall man.

\subsection{Preposition}

Louchene (2006) noted that the Arab grammarians defined prepositions as subset of particles which have no meaning in themselves, but have linking function with other parts of speech [15].

The Arab learners of English as second language make errors, when they use the preposition and adverbs. One of these errors is substituting the preposition (in) for (at). These errors were attributed to an inadequate knowledge of the target language in their performances [3].

Al-Bayatii investigated the errors which the Iraqi students of English as a foreign language make when they used the prepositions. The results indicated that these students omitted or substituted the prepositions, as result to the interference of their mother tongue, or the influence of the target language itself. For instance, substituting (in) with (at) (e.g., he was hunting at the morning) instead of (he was hunting in the morning) due to the overgeneralization. Moreover, they made errors of omission, and omitted essential preposition in the target language, as interference of their mother tongue (e.g. the tool.... the communication is) [2]. 
In the language of the children with autism, they made the same errors and substituted the appropriate prepositions or adverbs with inappropriate prepositions or adverbs, or omitted the prepositions and adverbs. Ahmed substituted the propositions $96 \%$ in his answers and omitted it 33\%, whereases Mohammad substituted the propositions $76 \%$ and omitted it $88 \%$ in his answers.

Table 2. Illustrates substituting (in, out, on, under, inside, outside) with (at) in the answers of the children with autism.

The dog is at the chair instead of the dog is on the chair.

The cat is at the box instead of the cat is in the box.

The boy is at the basket instead of the boy is inside the basket.

The boy is at the basket instead of the boy is outside the basket.

Table 3. Illustrates omitting the prepositions (in \& on) in the answers of the children with autism.

Bird flying sky instead of the bird is flying in the sky.

Airplane landed earth instead of the airplane landed on the earth

Table 4. Illustrates omitting the preposition (by) which should precede the reflexive pronouns (himself) in the following sentences.

He wears shirt (himself) instead of (by himself)

He wears shoes (himself) instead of (by himself)

He drinks juice (himself) instead of (by himself)

\subsection{Articles}

In Arabic, the definite articles never exist separately, it must be attached to the words. (Alif-laam) is used as definite article in Arabic, and attached to the Arabic nouns and adjectives as prefixes [22]. In Arabic, (Alif-laam) is the only definite article (e.g., the house (al-baytun), and there is no indefinite article but there are indefinite forms (e.g., house (baytun) [1]. The Omission and Addition of the definite article

The omission of the article (the) in the production of the EFL learners represented $16 \%$ of this type of errors and $40 \%$ of all the types of omissions, and considered as intralingual error. Whereas, the addition of the article (the) in the production of their target language represented $71 \%$ of this type of errors and of all addition errors type, and considered as interlingual error. The Arabic speakers overuse this article when they use their mother tongue, and it is reflected on their target language as well [7].

According to the two autistic children of this study, they omitted the article (the) in their speech as the EFL learners. Ahmed omitted the article (the) $51 \%$ and never overused it in his answers, in opposite to Mohammad who omitted the article (the) $62 \%$ in his answers and overused it $25 \%$.

Table 5. Illustrates omitting the article (the) in the answers of the children with autism.

(Fish swimming lake) instead of (The fish is swimming in the lake) (the definite article (the) which is (alif-laam) in Arabic should be attached to the noun (lake).

(Airplane flying sky) instead of (the Airplane is flying over the sky). (the Arabic definite article (alif-laam) should be attached to the noun (sky).
Table 6. Illustrates the overuse of the article (the) in the answers of the autistic children.

This face is crying (the tears) instead of (tears). The Arabic definite article (alif-laam) should not be attached to the noun (tears).

This face is (the happy) instead of (happy). The Arabic definite article (aliflaam) should not be attached to the adjective (happy).

In Durrleman \& Zufferey's (2009) study, Brett omitted the articles $17 \%$ in his production, and Roger increased the proportion and omitted it $23 \%$ in his production.

Examples

I want.... amusement park

..... Star going around.

\subsection{Subject-Verb Agreement}

In Arabic, verbs, nouns, pronouns and adjectives are marked for gender in its masculine or feminine forms. Moreover, verbs are marked for masculine or feminine by adding prefix or suffix or both of them based on the tense either present or past [4].

Examples

Ya-drusu (he studies).

Ta-drusu (she studies).

Muftah \& Rafik-Galea examined the errors which Arab ESL learners made when they used the $3^{\text {rd }}$ person singular. The findings of their study revealed that the ESL learners faced difficulty in using the $3^{\text {rd }}$ person singular, as result to the interference between their mother tongue and the target language. Moreover, their findings noted that all the groups omitted the $3^{\text {rd }}$ person singular in their production. For instance, the advanced group omitted it $6.67 \%$ in their production, the Upper-Intermediate group omitted it $8.00 \%$ in their production, and the lower-intermediate group omitted it $17.71 \%$ in their production [19].

Table 7. Illustrates the omission of the $3^{\text {rd }}$ person singular in the production of the ESL learners.

\section{Tam speak instead of Tam speaks. \\ Liam try instead of Liam tries. \\ He complain instead of he complains.}

In this study, the two autistic children omitted the prefixes ( T (/tā) which must be attached to the words to derive the feminine form, and replaced it with the masculine form to refer to both of them. In the current study, Ahmed omitted the prefix (T (/tā) 99\% in his answers and Mohammad omitted it $97 \%$ in his answers.

Table 8. Illustrates omitting the feminine prefix in the answers of the two autistic children in the subject-verb agreement sentences.

\begin{tabular}{ll}
\hline The girl buys & $\begin{array}{l}\text { Al-bint ya-shtaree instead of ta-shtaree (the feminine } \\
\text { prefix (ta) replaced with the masculine prefix (ya). }\end{array}$ \\
The boy buys & Al-walaad ya-shtaree (correct prefix). \\
The girl swims & $\begin{array}{l}\text { Al-bint ya-sbahu instead of ta-sbahu (the feminine } \\
\text { prefix (ta) replaced with the masculine prefix (ya). }\end{array}$ \\
The boy swims & Al-walaad ya-sbahu (correct prefix)
\end{tabular}

The verb (ya-shtaree) must be (ta-shtaree), and the masculine prefix (ya) must be replaced with the feminine 
prefix (ta). The verb (ya-sbahu) must be (ta-sbahu), and the masculine prefix (ya) must be replaced with the feminine prefix (ta).

Moreover, in Durrleman \&Zufferey's (2009) study, Brett omitted the third person singular $21 \%$ in his production of data, and Roger increased the proportion and omitted it $71 \%$ in his production of data.

Examples

He say that.

A cow make woof woof.

In Yusoff, Y. et. al.'s study, NZ (8 years old Malay girl with autism) used the third person singular (-s) correctly $72.92 \%$, most of her errors were to omit the (-s). For example, foggy catch the dogs but he catch too much dogs [27].

\subsection{Plurality}

There are two types of plural in Arabic which are the sound plural and the broken plural. The Sound Plural classified into (Masculine Sound Plural) and (Feminine Sound Plural). The Masculine Sound Plural can be formed by adding suffixes such as (oon) in the nominative case or (een) in the accusative and genitive cases to nouns to form the masculine sound plural. Whereas, the Feminine Sound Plural can be formed by adding suffixes such as (at) in the nominative case or (atee) in the accusative and genitive cases. The second type is the Broken Plural and can be formed by making changes in the singular nouns. For instance (Qalam) becomes (aqlam) [25].

Some Arab learners of English use the singular nouns after numbers as in the Arabic language instead of the plural nouns (e.g. he has 11 cousin instead of cousins) or (there are twenty one student instead of students) [24].

In the present study, the children with autism used the singular noun (pen) instead of the plural noun (pens) as in the ESL/EFL. For instance, they omitted the plural noun (s) and used (three pen) instead of (three pens) which is incorrect in Arabic.

Table 9. Illustrates replacing the plural nouns with singular nouns in the performance of the two autistic children in the sentences of plurality.

Three pen instead of three pens

Five telephone instead of five telephones

Six orange instead of six oranges

\section{Discussion}

Some of the verbal autistic children acquire their mother tongue at late age and this delay lead to errors in the production of their mother tongue, in opposite to the typically developing children who acquire their mother tongue earlier, and produce intact grammatical structure and vocabulary. The Arab learners of the second/foreign language make similar errors in the production of the target languages due to the delayed exposures to this language. In 1990, Newport attributed it to the maturation and focused on the effects of age in acquiring the native language or in learning the second /foreign language, and stressed on the significant difference between the performance of these learners before and after the maturation. Al-Bayatii (2013) stated that the EFL learners try to use the target language more simply and it results in producing errors. In the current study, the two autistic children used the same technique and tried to avoid the complex structures in the productions of their native language, and it resulted in errors as well. Also, this finding is in line with the finding of Eigsti's et. al. (2007) study which declared that the autistic children avoided the complex structures. Avoiding the complex structures in the productions of the two groups can be attributed to their delayed acquisition / learning of the native /target languages, and to their delayed and less exposure to these languages too. Furthermore, the findings of the current study revealed that there is no subject-verb agreement in the production of the autistic children, and this finding is in consistent with the findings of Bartolucci et. al. (1980), Roberts et. al. (2004), Eigsti et. al. (2009) and Durrleman et. al. (2009) which stated that there is no subject-verb agreement in the production of the autistic children as well due to the impaired use of the third person singular in their production. The impaired subject-verb agreement in the answers of the autistic children was also noted in Durrelmean et. al.'s (2009) findings where the two autistic children omitted the subjects, the subject auxiliary inversion and the auxiliary in their productions. Hence, the findings of Bartolucci et. al. (1980) and Durrleman et. al. (2009) agree with the findings of the present study which stated that the autistic children omitted the articles in their answers. The findings of the present study and the previous studies reported the errors in the productions of the autistic children, and the current study declared the similarities between these errors and the errors of the learners of the second/foreign language which stated in the previous studies.

\section{Conclusions \& Implication}

To conclude, the children with autism experience challenges in acquiring their spoken language normally and using it spontaneously, in opposite to the typically developing children who acquire it normally and develop it properly and gradually. These challenges are similar to the difficulties which face the Arab learners of the second/foreign language. The present study has attempted to identify various grammatical errors exist in the production of the autistic children. These errors are similar to the errors in the production of the foreign/second language learners. These errors included difficulties with ordering the adjectives at the sentence level, omitting the prepositions and adverbs or substituting them with inappropriate ones, omitting or overusing the article (the), replacing the feminine prefix with masculine prefix resulted in disagreement between the subjects and verbs, replacing the plural nouns with singular nouns in plurality. Furthermore, the current study focused on the primary reasons which led to the similarities between these errors and included delay in the acquisition of the mother tongue in the children with autism, and the delayed 
learning of the target language in learners of the second/foreign language. In addition to, impaired social interaction in the children with autism, and the lack of interaction with the native speakers in the learners of the second / foreign language. In this light, it is recommended using the techniques, tools, methods and curriculums of teaching the ESL/EFL in teaching the autistic children their mother tongue. These techniques and tools may include flash cards, songs, social stories, simple and short social movies, and mixing them with typically developing children socially in small groups and for specific hours weekly.

\section{References}

[1] Abu-Chacra, F. (2007). Arabic (An Essential Grammar). USA. New York. Routledge.

[2] Al-Bayati, W. (2013). Errors made by Iraqi EFL undergraduates in the use of prepositions. Bulletin of the transilvania University of Brasov. 6 (55) No. 1, 41-56.

[3] Al Khotaba, E.\& Al Karak, M. (2013). Errors in the Use of Prepositions and Adverb Particles by Arab ESL Speakers: Performance Analysis Perspective. International Journal of Linguistics, 5 (1), p: 273-282. doi: 10.5296/ijlv5i1.3310.

[4] Alhawary, M. (2011). Modern Standard Arabic Grammar. west Sussex. UK. Wiley-Blackwell.

[5] American Psychiatric Association (1994). DSM-IV: Diagnostic and statistical manual of mental disorders ( $4^{\text {th }} \mathrm{Ed}$.). Washington, DC: Author.

[6] American Psychiatric Association (2000). Diagnostic and statistical manual of mental disorder, text revision DSM IVTR, $4^{\text {th }}$ ed. Washington DC, American Psychiatric Association.

[7] Al-Qadi, M. M. (2017) English Article System Errors among Saudi Arab EFL Learners: A Case of the Preparatory Year English Program Learners of King Saud University. International Journal of English Language \& Translation Studies. 5 (1), 69-77.

[8] Bartolucci, G. \& Albers, R. J. (1974). Deictic Categories in the language of autistic children, Journal of Autism and Childhood Schizophrenia, 4, 131-141.

[9] Bartolucci, G., Pierce, S. J., \&Streiner, D. (1980). Crosssectional studies of grammatical morphemes in autistic and mentally retarded children. Journal of autism and developmental disorder, 10, 39-49.

[10] Belkadi, A. (2006). Language Impairments in Autism: Evidence Against Mind-Blindness. SOAS Working Papers in Linguistics 14, 3-13.

[11] Durrleman, S. \&Zufferey, S. (2009). The Nature of Syntactic Impairment in Autism. Rivista di Grammatica Generativa. 34, 57-86.
[12] Eigsti, I. - M., L, Bennetto, et al. (2007). "Beyond Pragmatics: morphosyntactic development in autism. "Journal of autism and developmental disorders 37, 107-1023.

[13] Eigsti, I.-M. and L. Bennetto (2009). Grammatically Judgments in Autism: deviance or delay. "Journal of child language 36 (5), 999-1021.

[14] Gernsbacher, M., Morson, E., Grace, E. J. (2015) Language Development in Autism. In book: Neurobiology of Language. 879-886. Doi: 10,1016/B978-0-12-407794-2.00070-5.

[15] Husni, R., Zaher, A. (2020). Working with Arabic Prepositions. London: Routledge.

[16] Johnson, J. S., \& Newport, E. L. (1989). Critical period effects in second language learning: The influence of maturational state on the acquisition of English as a second language. Cognitive Psychology, 21 (1), 60-99.

[17] Kanner, L. (1943). Autistic disturbances of affective contact. Nervous Child 2, 217-250.

[18] Kika, M. (2014). Autism Spectrum Disorder in Children and Language Delays in their Parents when Children. International Journal of Humanities Social Sciences and Education (IJHSSE), 1 (9), 18-21.

[19] Mufftah \& Rafik-Galea (2013). Error Analysis of Present Simple Tense in the Interlanguage of Adult Arab English Language Learners. English Language teaching. 6 (2), 146154.

[20] Newport, E. (1990). Maturational Constraints on Language Learning. Cognitive Science 14, 11-28.

[21] Roberts, J., Rice, M. and Tager-Flusberg, H. (2004). Tense Marking in Children with Autism. Applied Psycholinguistics $25,429-448$.

[22] Ryding, C. K. (2005). A Reference Grammar of Modern Standard Arabic. UK, Cambridge: Cambridge University Press.

[23] Ryding, K., and Mehall, D. (2005). Formal Spoken Arabic: Basic course. Washington, DC: Georgetown University Press.

[24] Sabbah, S. (2015). Negative Transfer: Arabic Language Interference to Learning English. Arab World English Journal (AWEJ) Special Issue on Translation. 4 (2015), 269-288.

[25] Wickens. G. (1980). Arabic Grammar. UK, Cambridge. Cambridge University Press.

[26] Wittke, K., Mastergeorge, AM, Ozonoff, S., Rogers. SJ., Naigles. LR. (2017). Grammatical Language Impairment in Autism Spectrum Disorder: Exploring Language Phenotypes Beyond Standardized Testing. Front Psychol. https//doi.org/10.3389/fpsyg.2017.00532.

[27] Yusoff, Y., Salehuddin, K., Abdullah, I., Toran, H. (2019). English Morphosyntactic performance of a high-functioning ASD child: Implications on ELT. Malaysian Journal of Learning and Instruction, 16 (1), 155-179. 